\title{
Position Regulation and Anti-Swing Control of Overhead Gantry Inverted Pendulum (GIP) using Different Soft-computing Techniques
}

\author{
Ashwani Kharola \\ $\mathrm{PhD}$ Scholar, Department of Mechanical Engineering, Graphic Era University, Dehradun, India. \\ Senior Research Fellow (SRF), Institute of Technology Management (ITM), \\ Defence Research \& Development Organisation (DRDO), Ministry of Defence, Govt. of India. \\ Landour Cantt, Mussoorie, Uttarakhand, India. \\ E-mail: ashwanidaa@gmail.com, 0135-2741642, 09557494750
}

\begin{abstract}
This paper presents a comparison study of different control strategies for stabilizing highly nonlinear Gantry inverted pendulum (GIP) system. The control objective was achieved using three different softcomputing techniques i.e. Fuzzy logic (FL), Adaptive neuro fuzzy inference system (ANFIS) and Neural networks (NN's). The results obtained from fuzzy controller were further optimized using ANFIS and NN's controllers. The performance parameters considered for analysis were Settling time (seconds), Maximum Overshoot (degree) and Steady state error. The simulation results that both fuzzy and ANFIS controllers were able to stabilize the non-linear GIP system within specified time. It was also observed that ANFIS controller shows better learning ability as compared to NN's controller. The study also elaborates the relationship between Membership functions (MF's) and training error tolerance for ANFIS controller and relation between hidden neurons and Mean squared error (MSE) and Regression (R) value for NN's controller.
\end{abstract}

Index Terms - Gantry inverted pendulum, Fuzzy Logic, ANFIS, NN's, Membership functions, FLC.

\section{INTRODUCTION TO GIP SYSTEM}

The basic configuration of GIP system comprises of a movable cart on which is mounted a rigid and massless pendulum. The pendulum is free to rotate without friction [1]. The dynamics of GIP resembles a Gantry crane, which is widely used in industries for transportation of suspended load [2]. These are highly non-linear systems and exhibits uncontrolled oscillations which causes both stability and safety hazards [3]. The objective is to quickly transfer the load to desired destination with minimum swing [4]. Recently various soft-computing techniques have been used for control and stabilization of GIP systems. Wahyudi and Jalani [5] designed an intelligent gantry crane system using fuzzy logic controllers which was further compared with classical PID controller. The results showed that fuzzy controllers were more robust to parameter variation as compared to
PID controllers. Al-Mousa [6] studied controllers based on two different techniques i.e. fuzzy and time delayed position feedback controller. The two controllers were further combined into a hybrid controller which showed good performance.

Mahfouf et al. [7] proposed a fuzzy logic based antisway control of overhead cranes. They designed a nonlinear model of overhead crane using two rule bases which takes into account a combination of both trolley and pendulum. The results indicate the feasibility of two rule base control strategy. Chang et al. [8] presented a twin fuzzy controller which deals with feedback information from position and swing angle of load. The proposed approach not only simplifies the designing procedure of crane but also reduces the number of fuzzy rules. Lee and Cho [9] proposed a fuzzy anti-swing control of a three-dimensional overhead crane. The control scheme consisted of position servo control and fuzzy logic control. The proposed controllers accurately controlled the crane position, rope length and suppresses load swing during hoisting and traverse motions of crane.

Choi et al. [10] proposed a neural network based two degree of freedom PID controller for controlling swing motion and position of gantry crane. Simulation results shows excellent performance of proposed controller. Bruins [11] presented a comparison between four control algorithm for gantry crane system. The different controllers were P-controller, cascade P-controller, fuzzy controller and an internal modal controller. Results showed that fuzzy controller gives best performance. Shojaei et al. [12] proposed a novel controller based on recurrent neural network and PID controller for Rotational inverted pendulum (RIP). They also presented an investigation study for stabilizing RIP using Genetic algorithm (GA). Solihin et al. [13] presented a fuzzy PID controller design for control of gantry crane. The proposed system utilizes fuzzy system as PID gain tuners for achieving desired performance. Arpaci and Ozguven [14] a non-linear model for an overhead crane system has been derived. An ANFIS controller has been developed and simulated in Matlab using training data from PID controller.

This paper elaborates a new methodological approach 
for comparative analysis of three different softcomputing techniques in Matlab. The comparison study is based on following control techniques i.e. fuzzy logic reasoning, ANFIS and Neural networks for position regulation and anti-swing control of GIP systems. The mathematical model of GIP was built in Matlab-Simulink and simulation results are shown with the help of graphs and tables which proved the validity of proposed study.

\section{MATHEMATICAL MODEL OF GIP SySTEM}

A two-dimensional view of GIP on cart is shown in figure 1.0 as considered from Pal and Mudi [15]. It comprises of a load of mass (m), attached to a cart of mass $(\mathrm{M})$ with a rigid pendulum of length $(\mathrm{L})$. The mass of the pendulum is considered to be negligible. A force $(\mathrm{u})$ is applied to the cart in horizontal direction $(\mathrm{x})$ while maintaining an angle $(\Theta)$ between pendulum and vertical axis $(y)$.

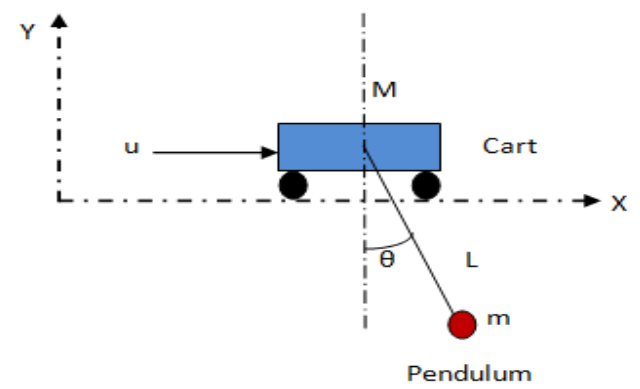

Fig.1.0. Gantry Inverted Pendulum

Mathematical modeling of GIP was done using Newton's second law "Ref. 16". The complete system was further divided into two subsystems i.e. cart and pendulum. The free body diagrams (FBD) of both the systems are shown in figure 1.1 and figure 1.2 respectively. Where, $\mathrm{F}$ is the longitudnal force exerted by the pendulum.

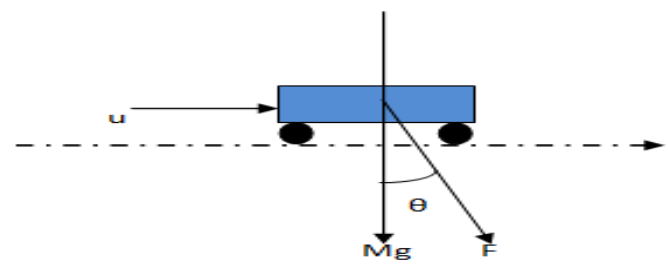

Fig.1.1 FBD of Cart

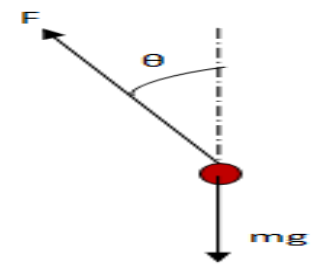

Fig.1.2. FBD of Pendulum
The governing mathematical equations for GIP system were derived using FBD of above sub-systems. The equations of motions for cart and pendulum systems are given below

(a) Equations for Cart

i. Along $X$-axis

$$
\mathrm{M} \ddot{x}=u+F \sin \theta
$$

ii. Along Y-axis

$$
F \cos \theta+M g=0
$$

(b) Equation for Pendulum

i. Along $X$-axis

$$
m \cdot \frac{d^{2}}{d t^{2}}(x+L \sin \theta)=-F \sin \theta
$$

ii. Along $Y$-axis

$$
m \cdot \frac{d^{2}}{d t^{2}}(L \cos \theta)=-F \cos \theta+m g
$$

The above equations were used for determining angular acceleration of pendulum $(\ddot{\Theta})$ and acceleration of cart $(\ddot{\mathrm{x}})$.

$$
\ddot{\theta}=\frac{-\left[u \cos \theta+m \sin \theta\left(L \dot{\theta}^{2} \cos \theta+g\right)+M g \sin \theta\right]}{\left(M+m \sin ^{2} \theta\right) L}
$$

$$
\ddot{x}=\frac{u+m \sin \theta\left(L \dot{\theta}^{2}+g \cos \theta\right)}{\left(M+m \sin ^{2} \theta\right)}
$$

Using eq. (5) and eq. (6) the Matlab Simulink model of GIP was build.

\section{BUILDING SIMULINK OF GIP SYSTEM}

Initially a Matlab Simulink of GIP was built which was further integrated into a sub-system. A view of GIP Simulink and its complete sub-system are shown in figure 1.3 and figure 1.4 respectively.

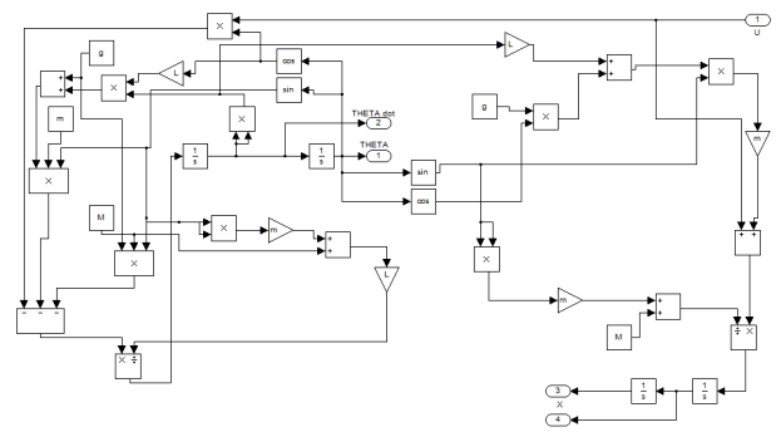

Fig.1.3. Simulink of GIP system 


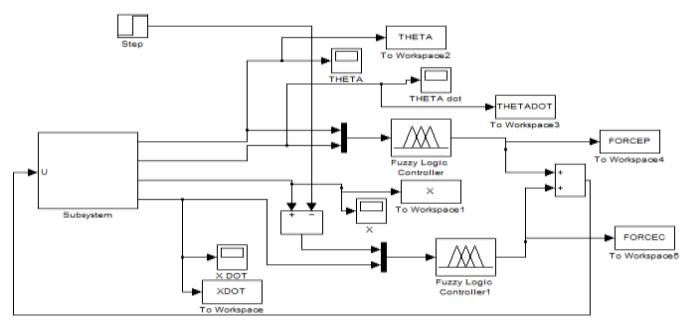

Fig.1.4. Simulink of GIP sub-system

\section{FUZZY CONTROL OF GIP SYSTEM}

The study considers Mamdani based fuzzy inference system (M-FIS) "Ref. 17" with gbell membership functions (MF's) "Ref. 18" for designing of Fuzzy logic controller (FLC's) "Ref. 19". The study considers seven linguistic variables (namely NL-negative large, NMnegative medium, NS-negative small, ZE-zero, PSpositive small, PM-positive medium and PL-positive large) for defining a set of 49 if-then fuzzy rules "Ref. 20". A view of gbell MF's and surface viewers for both cart and pendulum controllers are shown from figure 1.5 to figure 1.8 .

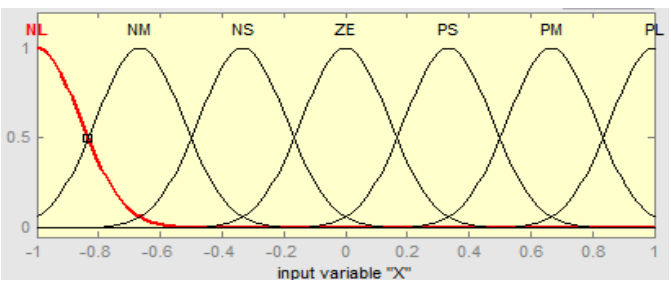

Fig.1.5. MF's for Cart position

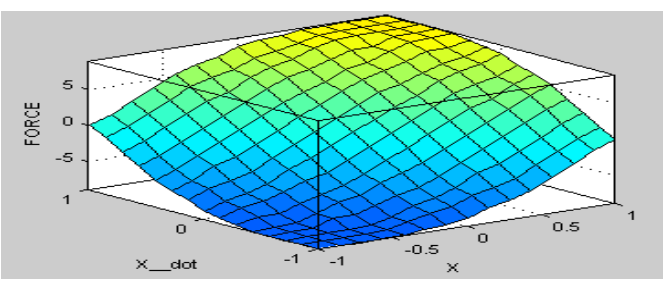

Fig.1.6 Surface viewer for Cart controller

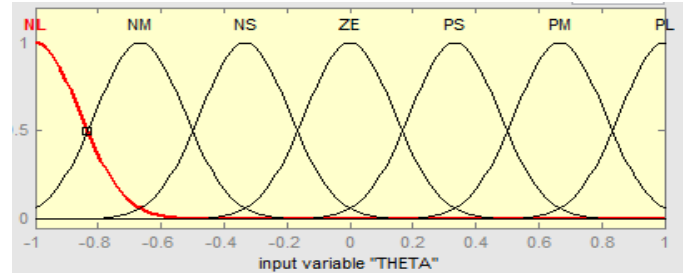

Fig.1.7 MF's for Pendulum angle

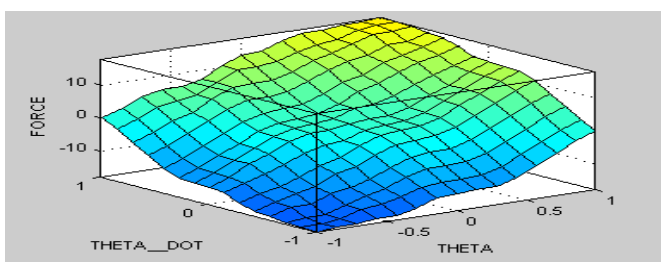

Fig.1.8 Surface viewer for Pendulum controller

\section{ANFIS CONTROL OF GIP SYSTEM}

ANFIS "Ref. 21" belongs to a class of artificial neural network "Ref. 22" which is based on Takagi-Sugeno fuzzy inference system "Ref. 23". The training in ANFIS was done using Hybrid learning algorithm "Ref. 24" which is a combination of Back-propagation "Ref. 25" and least square method "Ref. 26". The Grid partition method was further used for building an initial FIS structure.

A total of 65 data sets were collected from simulation results of fuzzy controller. These data sets were further used for training of ANFIS controller. The loading of data sets for cart and pendulum controller in ANFIS are shown in figure 1.9 and figure 2.0 respectively.



Fig.1.9 Loading of data sets for Cart controller

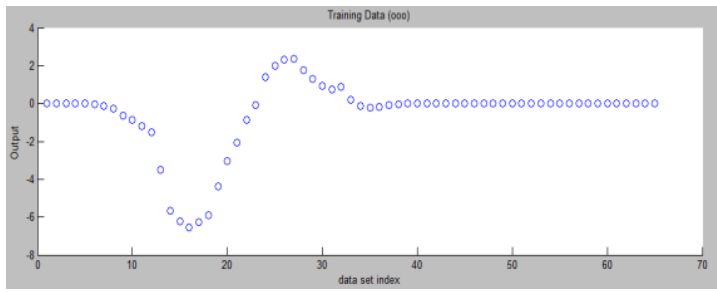

Fig.2.0 Loading of data sets for Pendulum controller

The training error tolerance for both cart and pendulum controllers were set to zero. The training of cart and pendulum controllers in ANFIS are shown in figure 2.1 and figure 2.2 respectively.

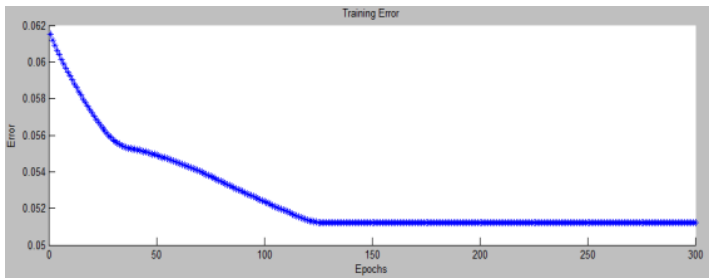

Fig.2.1 Training for Cart controller



Fig.2.2 Training for Pendulum controller

This study considers gaussian MF's (3 Nos.) for building FIS structure in ANFIS. During training the MF's and fuzzy rules were modified according to training 
data sets. A view of MF's and surface viewer obtained after training of cart controller are shown in figure 2.3 and figure 2.4 respectively.

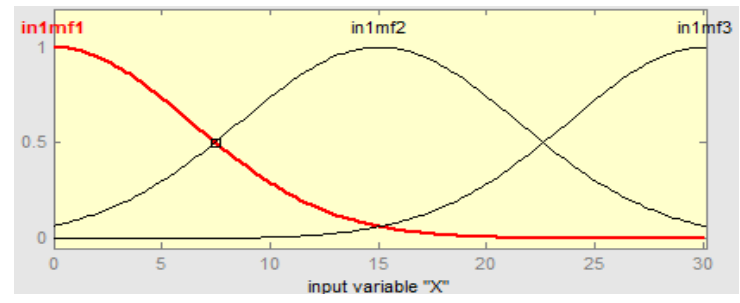

Fig.2.3 MF's for Cart position after training

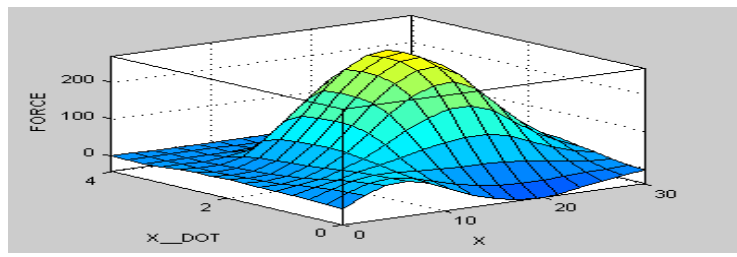

Fig.2.4 Surface viewer for Cart controller after training

In this study the relationship between number of MF's and training error has also been illustrated. A view of training error obtained for different number of MF's are shown in table 1.0.

Table 1.0 Error for cart and pendulum controllers

\begin{tabular}{|c|c|c|}
\hline $\begin{array}{c}\text { Nos. of } \\
\text { MF's }\end{array}$ & $\begin{array}{c}\text { Training Error } \\
\text { (Cart controller) }\end{array}$ & $\begin{array}{c}\text { Training Error } \\
\text { (Pendulum controller) }\end{array}$ \\
\hline 3 & 0.052373 & 0.012194 \\
\hline 4 & 0.039958 & 0.001448 \\
\hline 5 & 0.020751 & 0.0017271 \\
\hline 6 & 0.0041908 & 0.0012238 \\
\hline 7 & 0.0043663 & 0.0010999 \\
\hline 8 & 0.0034438 & 0.0011094 \\
\hline 9 & 0.0034577 & 0.0010848 \\
\hline 10 & 0.0030623 & 0.0011328 \\
\hline 11 & 0.002998 & 0.0010151 \\
\hline 12 & 0.0029749 & 0.0010933 \\
\hline 13 & 0.0029482 & 0.00085599 \\
\hline 14 & 0.00067823 & 0.00096947 \\
\hline
\end{tabular}

It is clearly observed from the table 1.0 that with increase in number of MF's the training error for the controllers decreases. Therefore an adequate number of MF's can considered for obtaining optimal training error.

\section{OUTPUT RESPONSES OF FUZZY AND ANFIS CONTROLLER}

The simulation time considered for the study was 10 sec. The values of different parameters considered for simulation are given in table 1.1

Table 1.1 Values of different parameters

\begin{tabular}{|l|c|}
\hline \multicolumn{1}{|c|}{ Parameter } & Value \\
\hline mass of cart $(\mathrm{M})$ & $1 \mathrm{Kg}$ \\
\hline mass of Pendulum $(\mathrm{m})$ & $0.1 \mathrm{Kg}$ \\
\hline acceleration due to gravity $(\mathrm{g})$ & $9.81 \mathrm{~m} / \mathrm{s}^{2}$ \\
\hline length of the pendulum (L) & $1 \mathrm{metre}$ \\
\hline
\end{tabular}

A view of output responses and comparison of performance parameters using fuzzy and ANFIS controllers are shown with the help of graphs and tables below.

\section{a. Cart Velocity Response}

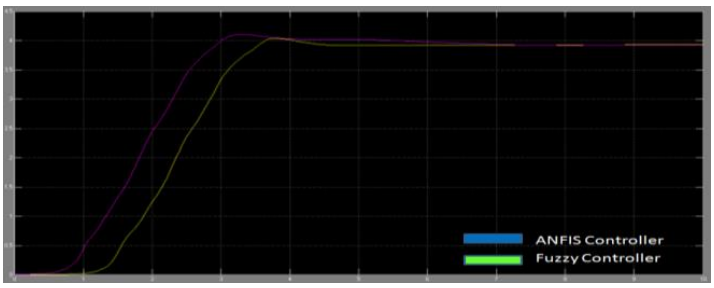

Fig.2.5 Cart velocity response for Fuzzy \& ANFIS controller

Table 1.2 Comparison of Cart velocity response

\begin{tabular}{|c|c|c|}
\hline $\begin{array}{c}\text { Performance } \\
\text { parameter }\end{array}$ & $\begin{array}{c}\text { Fuzzy } \\
\text { controller }\end{array}$ & $\begin{array}{c}\text { ANFIS } \\
\text { controller }\end{array}$ \\
\hline Settling time (sec) & $4.5 \mathrm{sec}$ & $4.0 \mathrm{sec}$ \\
\hline $\begin{array}{c}\text { Maximum } \\
\text { Overshoot (degree) }\end{array}$ & $4.0^{\circ}$ & $4.1^{\circ}$ \\
\hline Steady state error & 0 & 0 \\
\hline
\end{tabular}

b. Pendulum angle response

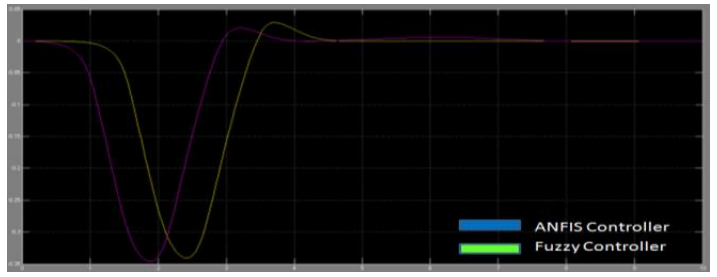

Fig.2.6 Pendulum angle response for Fuzzy \& ANFIS controller

Table 1.3 Comparison of Pendulum angle response

\begin{tabular}{|c|c|c|}
\hline $\begin{array}{c}\text { Performance } \\
\text { parameter }\end{array}$ & $\begin{array}{c}\text { Fuzzy } \\
\text { controller }\end{array}$ & $\begin{array}{c}\text { ANFIS } \\
\text { controller }\end{array}$ \\
\hline $\begin{array}{c}\text { Settling time } \\
\text { (sec) }\end{array}$ & $4.6 \mathrm{sec}$ & $4.0 \mathrm{sec}$ \\
\hline $\begin{array}{c}\text { Maximum } \\
\text { Overshoot } \\
\text { (degree) }\end{array}$ & $-0.33^{\circ}$ & $-0.33^{\circ}$ \\
to \\
\hline $\begin{array}{c}\text { Steady state } \\
\text { error }\end{array}$ & $0.03^{\circ}$ & $0.02^{\circ}$ \\
\hline
\end{tabular}

c. Pendulum angular velocity response

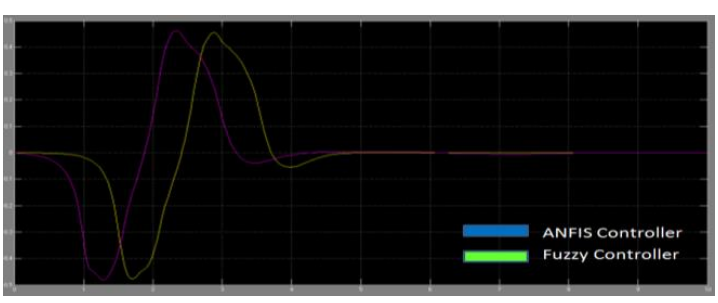

Fig.2.7 Pendulum angular velocity response for Fuzzy \& ANFIS controller

Table 1.4 Comparison of Pendulum angular velocity response

\begin{tabular}{|c|c|c|}
\hline $\begin{array}{c}\text { Performance } \\
\text { parameter }\end{array}$ & $\begin{array}{c}\text { Fuzzy } \\
\text { controller }\end{array}$ & $\begin{array}{c}\text { ANFIS } \\
\text { controller }\end{array}$ \\
\hline Settling time (sec) & $4.6 \mathrm{sec}$ & $4.2 \mathrm{sec}$ \\
\hline $\begin{array}{c}\text { Maximum } \\
\text { Overshoot (degree) }\end{array}$ & $-0.48^{\circ}$ & $-0.49^{\circ}$ \\
& to & to \\
& $0.44^{\circ}$ & $0.45^{\circ}$ \\
\hline Steady state error & 0 & 0 \\
\hline
\end{tabular}

I.J. Intelligent Systems and Applications, 2016, 2, 28-34 


\section{NN'S CONTROL OF GIP SYSTEM}

In this study we have used Neural network fitting tool (nftool) "Ref. 27" for designing of NN's controllers. Training of controllers was done using LevenbergMarquardt "Ref. 28" back-propagation algorithm. Training automatically stops when generalization stops improving, as indicated by increase in the Mean square error (MSE) of the validation samples. The MSE was used for measuring performance of the controllers. It is basically the average squared difference between outputs and targets. Lower values of MSE are considered better, zero means no error. Regression $(\mathrm{R})$ values measure the correlation between outputs and targets. An $\mathrm{R}$ value of 1 indicates a close relationship whereas $R$ value of 0 indicates a random relationship.

A total of 65 data sets or samples were collected from simulation results of fuzzy controllers. The data sets were further divided randomly into training, validation and testing samples. A view of randomly divided data is shown in table 1.5

Table 1.5 Randomly divided samples

\begin{tabular}{|c|c|c|}
\hline Samples & Percentage & Nos. of samples \\
\hline Training & $70 \%$ & 45 \\
\hline Validation & $15 \%$ & 10 \\
\hline Testing & $15 \%$ & 10 \\
\hline
\end{tabular}

The study also illustrates the effect of variation in number of hidden neurons $(\mathrm{N})$ on the MSE and R. During training, the network adapts to decrease the error on the training patterns. A view of values of MSE and $\mathrm{R}$ for different values of $\mathrm{N}$ are given in table 1.6.

Table 1.6 MSE \& R values for different number of hidden neurons

\begin{tabular}{|c|c|c|c|}
\hline \multicolumn{4}{|c|}{$\mathrm{N}=20$} \\
\hline & $\begin{array}{c}\text { Training } \\
\text { sample }\end{array}$ & $\begin{array}{c}\text { Validation } \\
\text { sample }\end{array}$ & $\begin{array}{l}\text { Testing } \\
\text { sample }\end{array}$ \\
\hline MSE & $4.7236 \mathrm{e}-4$ & $2.2388 \mathrm{e}-2$ & $1.3334 \mathrm{e}-2$ \\
\hline $\mathbf{R}$ & $9.9996 \mathrm{e}-1$ & $9.9835 \mathrm{e}-1$ & $9.9959 \mathrm{e}-1$ \\
\hline \multicolumn{4}{|c|}{$\mathrm{N}=21$} \\
\hline MSE & $2.7297 \mathrm{e}-3$ & $2.1750 \mathrm{e}-3$ & $3.3970 \mathrm{e}-2$ \\
\hline $\mathbf{R}$ & $9.9977 \mathrm{e}-1$ & $9.9968 \mathrm{e}-1$ & $9.9953 \mathrm{e}-1$ \\
\hline \multicolumn{4}{|c|}{$\mathrm{N}=22$} \\
\hline MSE & $1.3986 \mathrm{e}-2$ & $3.3647 \mathrm{e}-2$ & $1.8557 \mathrm{e}-2$ \\
\hline $\mathbf{R}$ & $9.9939 \mathrm{e}-1$ & $9.9795 \mathrm{e}-1$ & $9.9911 \mathrm{e}-1$ \\
\hline \multicolumn{4}{|c|}{$\mathrm{N}=23$} \\
\hline MSE & $1.5480 \mathrm{e}-2$ & $8.6439 \mathrm{e}-3$ & $1.6635 \mathrm{e}-2$ \\
\hline $\mathbf{R}$ & $9.9837 \mathrm{e}-1$ & $9.9942 \mathrm{e}-1$ & $9.9961 \mathrm{e}-1$ \\
\hline \multicolumn{4}{|c|}{$\mathrm{N}=24$} \\
\hline MSE & $5.7634 \mathrm{e}-3$ & $1.7234 \mathrm{e}-3$ & $2.0782 \mathrm{e}-2$ \\
\hline $\mathbf{R}$ & $9.9992 \mathrm{e}-1$ & $9.9989 \mathrm{e}-1$ & $9.9621 \mathrm{e}-1$ \\
\hline \multicolumn{4}{|c|}{$\mathrm{N}=25$} \\
\hline MSE & $6.4066 \mathrm{e}-3$ & $1.4475 \mathrm{e}-3$ & $8.1264 \mathrm{e}-3$ \\
\hline $\mathbf{R}$ & $9.9941 \mathrm{e}-1$ & $9.9986 \mathrm{e}-1$ & $9.9983 \mathrm{e}-1$ \\
\hline
\end{tabular}

As can been seen from table 1.6 the values of MSE and $\mathrm{R}$ changes with $\mathrm{N}$. Therefore an adequate number of neurons $(\mathrm{N})$ can considered for obtaining optimal values of MSE and R. The training of samples multiple times will generate different results due to different initial conditions and sampling. Neural network architecture was build using 20 neurons in the hidden layer and 1 neuron in the output layer. A view of neural network architecture is shown in figure 2.8

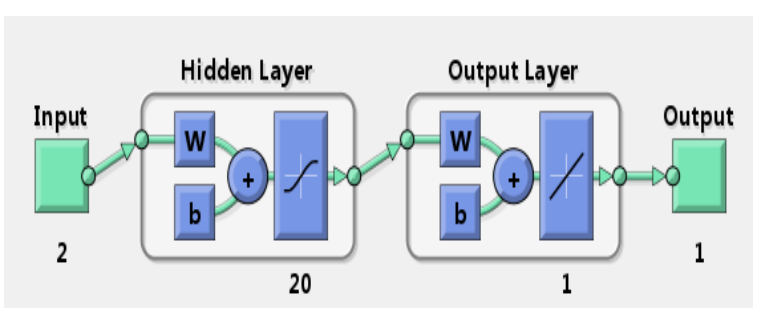

Fig.2.8 Neural network architecture

The Regression (R) plots for training, validation, testing sample and overall regression response after training of 20 neurons in the hidden layer are shown from figure 2.9 to figure 3.2 .

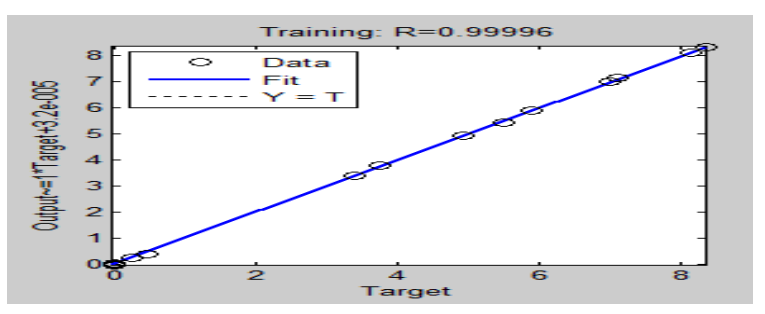

Fig.2.9 Regression response for training sample

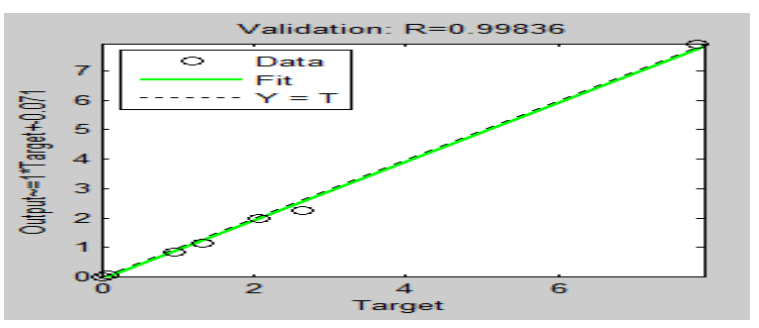

Fig.3.0 Regression response for validation sample

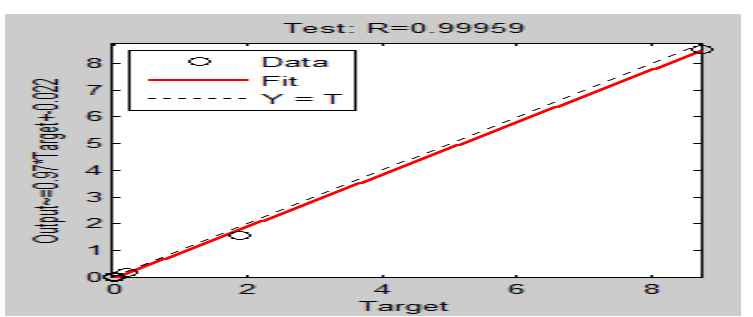

Fig.3.1 Regression response for testing sample



Fig.3.2 Overall Regression response 


\section{OUTPUT RESPONSES OF NEURAL NETWORK CONTROLLERS}

The output responses for cart and pendulum using NN's controller are shown from figure 3.3 to figure 3.6. The results shows that NN's controller was not able to control the GIP system. Hence further refinement in values of MSE and R is needed for improvement.

\section{a. Cart response}

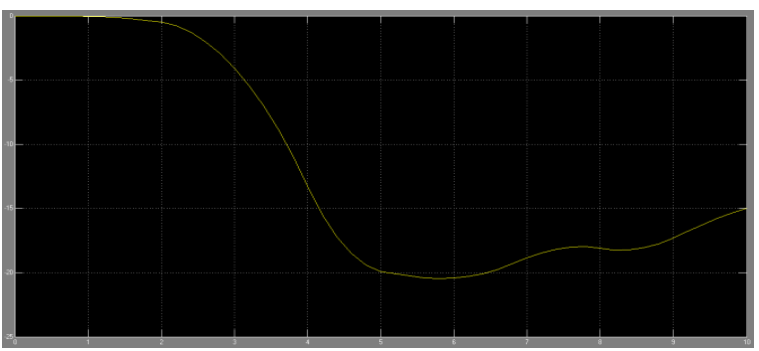

Fig.3.3 Cart position response

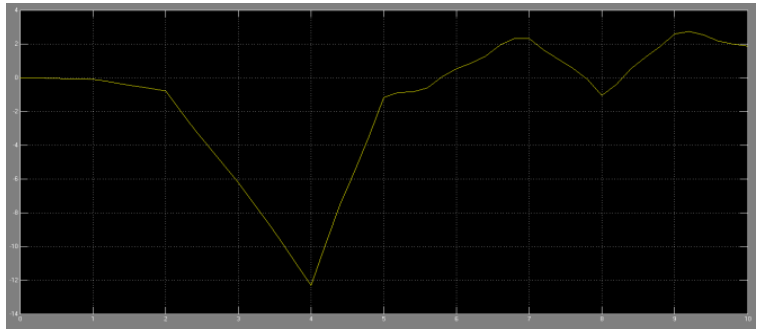

Fig.3.4 Cart velocity response

\section{b. Pendulum response}

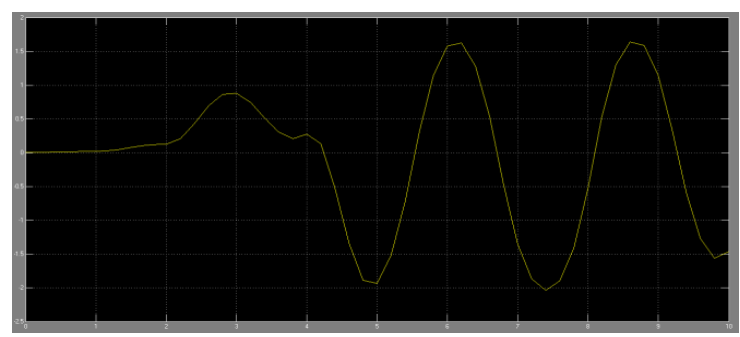

Fig.3.5 Pendulum angle response

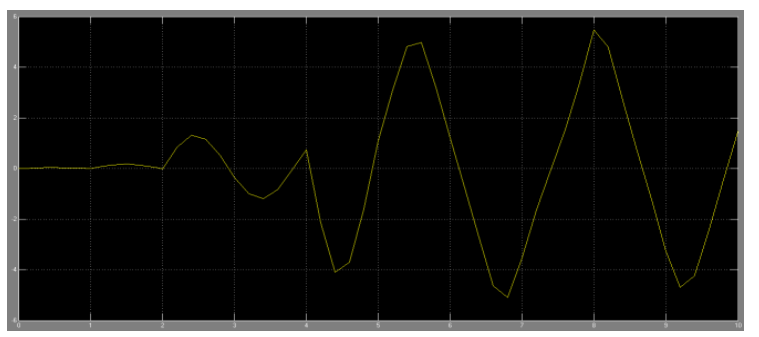

Fig.3.6 Pendulum angular velocity response

\section{CONCLUSION}

The control objective of this study to apply different soft computing techniques for stabilization of GIP system has been achieved. It is observed from the simulation results that both fuzzy and ANFIS controllers were able to stabilize the non-linear GIP system. The ANFIS controller shows better results in terms of settling time. The ANFIS controller stabilizes the system within $4.2 \mathrm{sec}$ whereas fuzzy controller takes $4.6 \mathrm{sec}$ to control the complete GIP system. Both of these controllers shows excellent response in terms of maximum overshoot and steady state error. It is observed that ANFIS technique shows an excellent learning ability with negligible training error. The training error obtained using 3 MF's for cart and pendulum controller were 0.052373 and 0.012194 respectively. It is also concluded that with increase in number of MF's the training error tolerance for ANFIS controllers decreases.

The NN's controller shows a good learning ability with overall Regression value of 0.99957 using 20 neurons in the hidden layer. The NN's controller was unable to stabilize the GIP system (refer figure 3.3 to figure 3.6). It was also observed that $\mathrm{R}$ and MSE values changes with variation in the number of hidden neurons $(\mathrm{N})$. Therefore an optimal number of hidden neurons can be selected for proper designing of NN's controllers. It is also recommended to apply other optimization techniques like Genetic algorithm (GA) "Ref. 29", Particle swarm optimization (PSO) "Ref. 30", Sliding mode control "Ref. $31 "$ for control and stabilization of non-linear and complex GIP systems.

\section{REFERENCES}

[1] Lilly JH (2010) Fuzzy Control and Identification. Wiley, ISBN: 978-0-470-54277-4.

[2] Mohd Zaki SSB (2008) Anti-swing and positioning control of a Gantry crane system using Fuzzy logic controllers. A report submitted for the award of Bachelor of Electronics Engineering, Faculty of Electronics and Computer Engineering, Universiti Teknikal Malaysia Melaka.

[3] Omar HM (2003) Control of Gantry and Tower cranes. A Doctoral Thesis submitted to the Department of Engineering Mechanics, faculty of the Virginia Polytechnic Institute and State University.

[4] Kaur A, Priyahansha, Kumari S, Singh T (2014) Position control of overhead cranes using fuzzy controllers. International Journal of Advanced research in Electrical, Electronics and Instrumentation Engineering 3(5):93419350.

[5] Wahyudi, Jalani J (2006) Robust fuzzy logic controller for an intelligent gantry crane system. In Proceedings of IEEE 1st International Conference on Industrial and Information Systems (ICIIS), 8-11 August 2006, Srilanka, pp 497-502. doi: 10.1109/ICIIS.2006.365778.

[6] Al-Mousa AA (2000) Control of rotary crane using fuzzy logic and time delayed position feedback control. A Master thesis submitted to the Dept. of Electrical Engineering, Faculty of the Virginia Polytechnic Institute and State University, Blacksburg, Virginia.

[7] Mahfouf M, Kee CH, Abbod MF, Linkers DA (2000) Fuzzy logic-based anti-sway control design for overhead cranes. Neural Computing \& Applications 19(1):38-43. doi: $10.1007 / \mathrm{s} 005210070033$.

[8] Chang C, Hsu S, Chiang K (2005) A practical fuzzy controllers scheme of overhead crane. Journal of Control Theory and Applications 3(3): 266-270, doi: 10.1007/s11768-005-0047-9. 
[9] Lee HH, Cho SK (2001) A new fuzzy-logic anti-swing control for industrial three-dimensional overhead cranes. In Proceedings of IEEE International Conference on Robotics and Automation, 21-26 May 2001, pp 29562961. doi: 10.1109/ROBOT.2001.933070.

[10] Choi SU, Kim JH, Lee JW, Lee YJ, Lee KS (2001) A study on gantry crane control using neural network two degree of PID controller. In Proceedings of IEEE International Symposium on Industrial Electronics (ISIE), 12-16 June, 2001, Pusan, pp 1896-1900. doi: 10.1109/ISIE.2001.932001.

[11] Bruins S (2010) Comparison of different control algorithms for a gantry crane system. Vol 1, pp 68-81. doi 10.423/ica.2010./2008.

[12] Shojaei AA, Othman MF, Rahmani R, Rani MR (2011) A hybrid control scheme for a Rotational inverted pendulum. In Proceedings of 5th IEEE UKSim European Symposium on computer modeling and simulations (EMS), 16-18 Nov 2011, Madrid, pp 83-87. doi: 10.1109/EMS.2011.79.

[13] Solihin MI, Wahyudi, Legowo A (2010) Fuzzy-tuned PID anti-swing control of automatic gantry crane. Journal of Vibration 16(1):127-145. doi: 10.117711077546309103421 .

[14] Arpaci H, Ozguven OF (2011) ANFIS and PID controller design and comparison for overhead cranes. Indian Journal of Engineering and Material Sciences 18:191-203.

[15] Pal AK, Mudi, RK (2013) An adaptive PD type FLC and its real time implementation to overhead crane control. International Journal of Emerging Technologies in computational and applied sciences 6(2):178-183.

[16] Zairulazha Z (2005) Modeling and Vibration control of a Gantry crane. A Master's Thesis submitted to Department of Electrical- Mechatronics and Automatic Control, Universiti Teknologi Malaysia.

[17] Cao SG, Rees NW, Feng G (2001) Mamdani-type fuzzy controllers are universal fuzzy controllers. Fuzzy Sets and Systems 123(3):359-367. doi: 10.1016/S01650114(01)00015-X.

[18] Hong TP, Lee CY (1996) Induction of fuzzy rules and membership functions from training examples. Fuzzy Sets and Systems 84(1):33-47. doi: 10.1016/01650114(95)00305-3.

[19] Lee CC (1990) Fuzzy logic in Control systems: fuzzy logic controllers. IEEE Transactions on Systems, Man and Cybernetics 20(2):404-418, doi: 10.1109/21.52551.

[20] Perfilieva I (2006) Fuzzy if-then rules from logical point of view. A book title Computational Intelligence, Theory and application and subtitle International Conference 9th fuzzy days in Dortmund, pp. 691-697. doi: 10.1007/3540-34783-6_67.

[21] Dalecky S, Zboril FV (2015) An approach to ANFIS Performance. A book title Mendel 2015 and series title Advances in Intelligent Systems and Computing, Vol. 378, pp. 195-206, doi: 10.1007/978-3-319-19824-8_16.

[22] Livingstone DJ (2009) A book title Artificial Neural Networks Methods and Applications. doi: 10.1007/978-160327-101-1, ISBN (print): 978-1-58829-718-1, ISSN: 1064-3745.

[23] Cherkassky V (1998) Fuzzy inference systems: A critical review. A book title Computational Intelligence: Soft computing and fuzzy neuro integration with applications and series title NATO ASI series, pp. 177-197. doi: 10.1007/978-3-642-58930-0_10.

[24] Pfister M, Rojas R (1994) Hybrid learning algorithm for feedforward neural networks. A book title Fuzzy logik and series title Informatik aktuell, pp. 61-68. doi:
10.1007/978-3-642-79386-8_8.

[25] Li J, Cheng JH, Shi JY, Fei-Juang (2012) Brief Introduction of Back Propagation (BP) neural networks algorithm and its improvement. A book title Advances in Computer Science and Information Engineering and series title Advances in Intelligent Soft computing, vol 169, pp. 553-558. doi: 10.1007/978-3-642-30223-7_87.

[26] Welberg J (2006) A book title Data analysis using the method of least squares and subtitle Extracting the most information from experiments.

[27] Demuth H, Beale M, Hagan M (2015) Neural Network Toolbox user guide

[28] More JJ (1978) The Levenberg-Marquardt algorithm: Implementation and theory. A book title Numerical Analysis and series title Lecture notes in Mathematics, Vol. 630, pp. 105-116. doi: 978-3-540-35972-2.

[29] Soukkou A, Khellaf A, Leulmi S (2004) Control of overhead cranes by Fuzzy-PID with Genetic optimization. In Proceedings of 1 st International Conference on Artificial Intelligence Application and Innovations (AIAI), 22-27 Aug 2004, Toulouse, France, pp. 67-80. doi: 10.1007/1-4020-8151-0_7.

[30] Wang Z, Chen Z, Zhang J (2012) On PSO based fuzzy neural network sliding mode control for overhead crane. A book title Practical Applications of Intelligent Systems and series title Advances in Intelligent and Soft computing, Vol. 124, pp. 563-572. doi: 10.1007/978-3642-25658-5-67.

[31] Chen ZM, Meng WJ, Zhang JG (2012) Intelligent antiswing control for bridge crane. Journal of Central South University 19(10):2774-2781. doi: 10.1007/s11771-0121341-6.

\section{Author's Profile}



Ashwani Kharola received B.Tech (with Honors) in Mechanical Engineering from Dehradun Institute of Technology, Dehradun in 2010 and M.Tech in CAD/CAM \& Robotics from Graphic Era University, Dehradun in 2013. He obtained Silver Medal in M.Tech for (2011-13) batch Currently he is working as Senior Research Fellow (SRF) in Institute of Technology Management (ITM), One of premier training institute of Defence Research \& Development Organisation (DRDO), Ministry of Defence, Govt. of India. He is also pursuing $\mathrm{PhD}$ in Mechanical Engineering from Graphic Era University (Deemed University), Dehradun. $\mathrm{He}$ has published 22 National/International papers in peer reviewed ISSN Journals and IEEE Conferences. His current areas of work includes Fuzzy logic reasoning, Adaptive Neurofuzzy inference system (ANFIS) control, Neural Networks, Mathematical Modeling \& Simulation of variants of non-linear Inverted pendulum (IP)systems etc.

How to cite this paper: Ashwani Kharola, "Position Regulation and Anti-Swing Control of Overhead Gantry Inverted Pendulum (GIP) using Different Soft-computing Techniques", International Journal of Intelligent Systems and Applications (IJISA), Vol.8, No.2, pp.28-34, 2016. DOI: 10.5815/ijisa.2016.02.04 